\title{
ERRATUM
}

P. A. J. Leegwater $\cdot$ P. K. I. Boor · B. Q. Yuan

J. van der Steen - A. Visser - A. A. M. Könst

C. B. M. Oudejans $\cdot$ R. B. H. Schutgens $\cdot$ J. C. Pronk

M. S. van der Knaap

\section{Identification of novel mutations in MLC1 responsible for megalencephalic leukoencephalopathy with subcortical cysts}

Published online: 14 June 2002

(C) Springer-Verlag 2002

\section{Hum Genet (2002) 110:279-283}

One of the grants received by the authors was omitted from the acknowledgements. The full text is as follows:

Acknowledgements We thank the families of patients and the referring doctors for their participation. J. M. Powers is acknowledged for critical reading of the manuscript. This work was supported by the Dutch Organisation for Scientific Research (NWO, grant 903-42-097) and the Hersenstichting (grant 8F00.2.01).

The online version of the original article can be found at http://dx.doi.org/10.1007/s00439-002-0682-x

P.A.J. Leegwater · P.K.I. Boor - B.Q. Yuan - J. van der Steen A. Visser - J.C. Pronk · M.S. van der Knaap

Department for Child Neurology,

Free University Medical Center, Amsterdam, The Netherlands

P.A.J. Leegwater · A.A.M. Könst · C.B.M. Oudejans

R.B.H. Schutgens

Department for Clinical Chemistry,

Free University Medical Center, Amsterdam, The Netherlands

J. van der Steen · J.C. Pronk

Department for Human Genetics,

Free University Medical Center, Amsterdam, The Netherlands

J.C. Pronk (头)

Department of Clinical and Human Genetics,

Free University Medical Center,

Van der Boechorststraat 7, 1081 BT Amsterdam, The Netherlands

e-mail: jc.pronk.humgen@med.vu.nl,

Tel.: +31-20-4448270, Fax: +31-20-4448285 